\title{
Mucosa-Associated Lymphoid-Tissue Lymphoma of the Cecum and Rectum: A Case Report
}

\author{
Myung Jin Nam, Byung Chang Kim, Sung Chan Park, Chang Won Hong, Kyung Su Han, Dae Kyung Sohn, \\ Weon Seo Park ${ }^{1}$, Hee Jin Chang, Jae Hwan Oh \\ Center for Colorectal Cancer, Research Institute and Hospital, National Cancer Center, Goyang; ${ }^{1}$ Center for Prostate Cancer, Research \\ Institute and Hospital, National Cancer Center, Goyang, Korea
}

A colonic mucosa-associated lymphoid-tissue (MALT) lymphoma is relatively rare compared to lymphomas of the stomach or small intestine. We present a case of a MALT lymphoma in the cecum and rectum found during screening colonoscopy. A 54-year-old female, who had undergone right-breast-conserving surgery with axillary dissection due to an invasive ductal carcinoma and a left-breast excisional biopsy due to microcalcification following adjuvant chemoradiation therapy 3 years earlier, was found to have 3-mm-sized smooth elevated lesions in both the cecum and rectum. No pathologic lesion or lymphadenopathy was found at any other site, but chronic gastritis negative for Helicobacter pylori infection was found. The polyps were removed by using an endoscopic biopsy and revealed an extra nodal marginal zone B-cell MALT lymphoma, showing positive for CD3 and CD20 by immunohistochemical staining. The patient underwent close observation without any additional treatment and has shown no evidence of recurrence as of her last visit.

Keywords: MALT lymphoma; Cecum; Rectum; Colonoscopy

\section{INTRODUCTION}

A primary malignant lymphoma occurring in the large intestine is a rare disease and accounts for less than $1 \%$ of all malignant colorectal neoplasms, of these, mucosa-associated lymphoid-tissue (MALT) lymphomas accounts for a small portion of gastrointestinal lymphomas $[1,2]$. Recently, The MALT lymphoma was categorized as an extra nodal marginal zone B-cell lymphoma by the World Health Organization, and an extra nodal marginal zone B-cell lymphoma is a subtype of non-Hodgkin's lymphoma and accounts for about $5 \%$ of all non-Hodgkin lymphomas [2].

A MALT lymphoma has been histologically characterized as a lymphoepithelial lesion with lymphoplasmic epithelial invasion.

Received: January 27, 2016 - Accepted: October 24, 2016

Correspondence to: Byung Chang Kim, M.D.

Center for Colorectal Cancer, Research Institute and Hospital, National

Cancer Center, 323 Ilsan-ro, Ilsandong-gu, Goyang 10408, Korea

Tel: +82-31-920-1649, Fax: +82-31-920-0002

E-mail: mdzara@ncc.re.kr

(C) 2017 The Korean Society of Coloproctology

This is an open-access article distributed under the terms of the Creative Commons Attribution NonCommercial License (http://creativecommons.org/licenses/by-nc/4.0) which permits unrestricted noncommercial use, distribution, and reproduction in any medium, provided the original work is properly cited.
Although a MALT lymphoma can occur in many parts of the body, the most predominant site is the alimentary tract. Along the gastrointestinal (GI) tract, the stomach and the small bowel are sites for about $60 \%$ and $30 \%$ of GI lymphomas, respectively. Gastric MALT lymphomas are associated with Helicobacter pylori infection, and the eradication of $H$. pylori could lead to regression of a low-grade MALT lymphoma of the stomach [3]. To the best of our knowledge, a few reports have been published about colorectal MALT lymphomas, but none establishing standard treatments has yet to be published. In the present paper, we describe a patient without symptoms who had a MALT lymphoma arising in the cecum and rectum that was detected accidentally during screening colonoscopy. We also present a review several recent reports in the literature published in English, Japanese, and Korean.

\section{CASE REPORT}

An asymptomatic 54-year-old woman visited our clinic for a health medical examination. Three years earlier, she had undergone right-breast-conserving surgery with axillary dissection due to an invasive ductal carcinoma and a left-breast excisional biopsy due to microcalcification following adjuvant chemo-radiation therapy in the Center for Breast Cancer and had shown no evi- 
dence of a recurrent lesion. She had no history of weight loss, fever or any other significant symptom. Blood evaluation revealed hemoglobin $12.3 \mathrm{~g} / \mathrm{dL}$, white blood cells $3,400 / \mathrm{mm}^{3}$ (neutrophil $23.8 \%$, lymphocyte $39.1 \%$, monocyte $4.4 \%$, and eosinophil $2.1 \%$ ), platelets $209,000 / \mathrm{mm}^{3}$, blood urea nitrogen $10.0 \mathrm{mg} / \mathrm{dL}$, creatinine $0.8 \mathrm{mg} / \mathrm{dL}$, total protein $7.2 \mathrm{~g} / \mathrm{dL}$, serum albumin $4.7 \mathrm{~g} / \mathrm{dL}$, aspartate aminotransferase $16 \mathrm{IU} / \mathrm{L}$, alanine transferase $11 \mathrm{IU} / \mathrm{L}$, total bilirubin $0.6 \mathrm{mg} / \mathrm{dL}$, and alkaline phosphatase $83 \mathrm{IU} / \mathrm{L}$; carcinoembryonic antigen levels were within the normal range. Abdominal contrast computed tomography and whole body positron-emission tomography scans demonstrated neither abnormal lesions nor enlargement of lymph nodes. She was diagnosed as having chronic gastritis due to a negative for $H$. pylori infection by using upper endoscopy. She had no family history of tumors.

Colonoscopy revealed an about 3-mm-sized, flat, elevated lesion in the cecum (Fig. 1A) and a type-IIa polyp $3 \mathrm{~mm}$ in size in the rectum, $1 \mathrm{~cm}$ above the anal verge (Fig. 1B). All polyps were removed by using endoscopic biopsy forceps. Histologic sections of the biopsies stained with hematoxylin and eosin showed lymphoepithelial lesions with dense infiltration of lymphoid cells effacing the glandular architecture and centrocyte-like cells in the lamina propria (Fig. 2A), suggesting an extra nodal marginal zone B-cell MALT lymphoma of both the cecum and rectum. Immunohistochemistry on both blocks was positive for $\mathrm{CD} 3$ and $\mathrm{CD} 20$ (Fig. 2B) and lymphoepithelial lesions, but negative for CD30 and Ki-67. Polymerase chain reaction analyses revealed negative values in gene rearrangements for the monoclonal immunoglobulin heavy chain and the T-cell receptor. These findings were compatible with a MALT lymphoma of the colon and rectum.

The patient was referred to the hemato-oncologic clinic for management, but she decided to keep close observation without any additional treatment because the lesion had been completely removed. We carried out antibiotic treatment, 7-day course of omeprazole, amoxicillin and clarithromycin, for $\mathrm{H}$. pylori eradication. Three months later, colonoscopy revealed no histological ev-

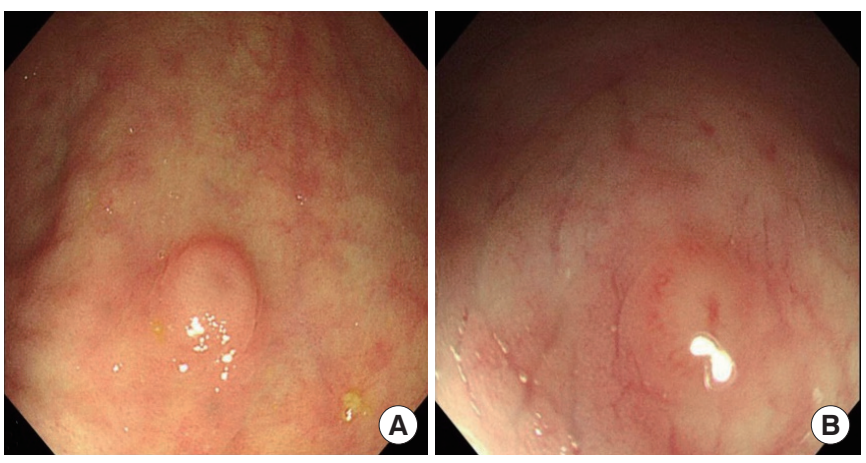

Fig. 1. (A) A 3-mm-sized, flat, elevated polyp was noted in the cecum. (B) A 3-mm-sized, type-IIa polyp was noted in the rectum 1 $\mathrm{cm}$ above the anal verge. idence of a MALT lymphoma at the cecum and rectum. At 6 months and 21 months after initial diagnosis, colonoscopy examinations revealed no recurrent lesion. The patient has been on a regular followed-up schedule at the outpatient clinic and last visited without any recurrence of the disease in November 2015.

\section{DISCUSSION}

Isaacson and Wright first introduced the concept of a lymphoma of the MALT type in 1983, and MALT-type lymphomas usually arise in organs originally devoid of lymphoid tissue and are acquired by persistent antigenic stimulation triggered by infectious or autoimmune processes $[2,4,5]$. We searched MEDLINE and PubMed for English, Japanese and Korean language articles from 2010 to 2015 by using the terms "MALT," "colon," and "rectum." A few published case reports on patients with primary colorectal MALT lymphomas were found, and most of the reported cases were from Japan, Korea and Taiwan, except for one case from the United States. These are summarized in the Table 1. Nevertheless, a treatment of for a primary MALT lymphoma occurring in the colon and rectum has yet to be identified.

A median-sized colorectal MALT lymphoma was reported to be $1.8 \mathrm{~cm}$, and 5 of the 13 patients were reported to have been treated by using an endoscopic mucosal resection or an endoscopic submucosal dissection $[6,7]$. Shaheen and Guddati [5] from the USA reported complete regression of a MALT lymphoma that had been detected in the entire colon and rectum following chemotherapy with rituximab for a patient with a past medical history of a right-colon adenocarcinoma treated with a right hemicolectomy.

Whether a colorectal MALT lymphoma is related to $H$. pylori infection is unclear, but a MALT lymphoma of the rectum was reported to have regressed after eradication therapy for $H$. pylori even though such an infection was absent, suggesting that microorganisms other than $H$. pylori may play a role in the pathogenesis
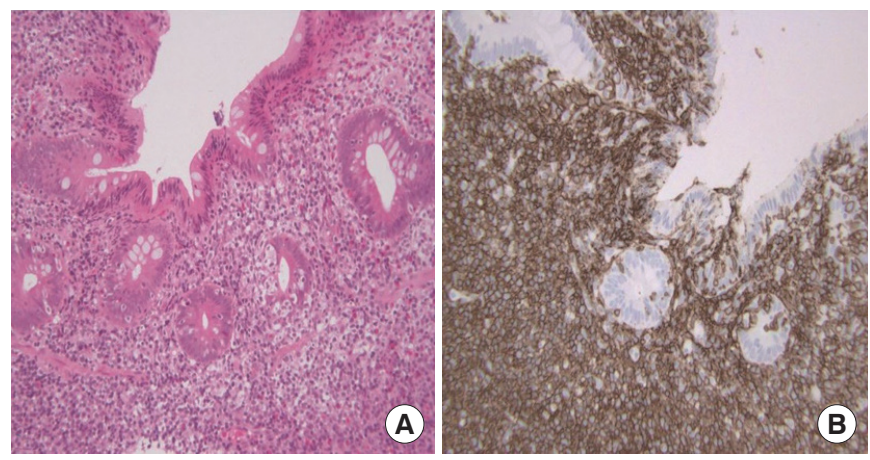

Fig. 2. (A) Lymphoepithelial lesion with dense infiltration of lymphoid cells in the lamina propria $(H \& E, \times 200)$. (B) Diffuse expression of CD20 suggesting a B-cell lineage of the lymphoid cells, as observed using immunohistochemical staining $(\times 200)$. 
Table 1. Summary of recent cases of colorectal mucosa-associated lymphoid-tissue lymphomas

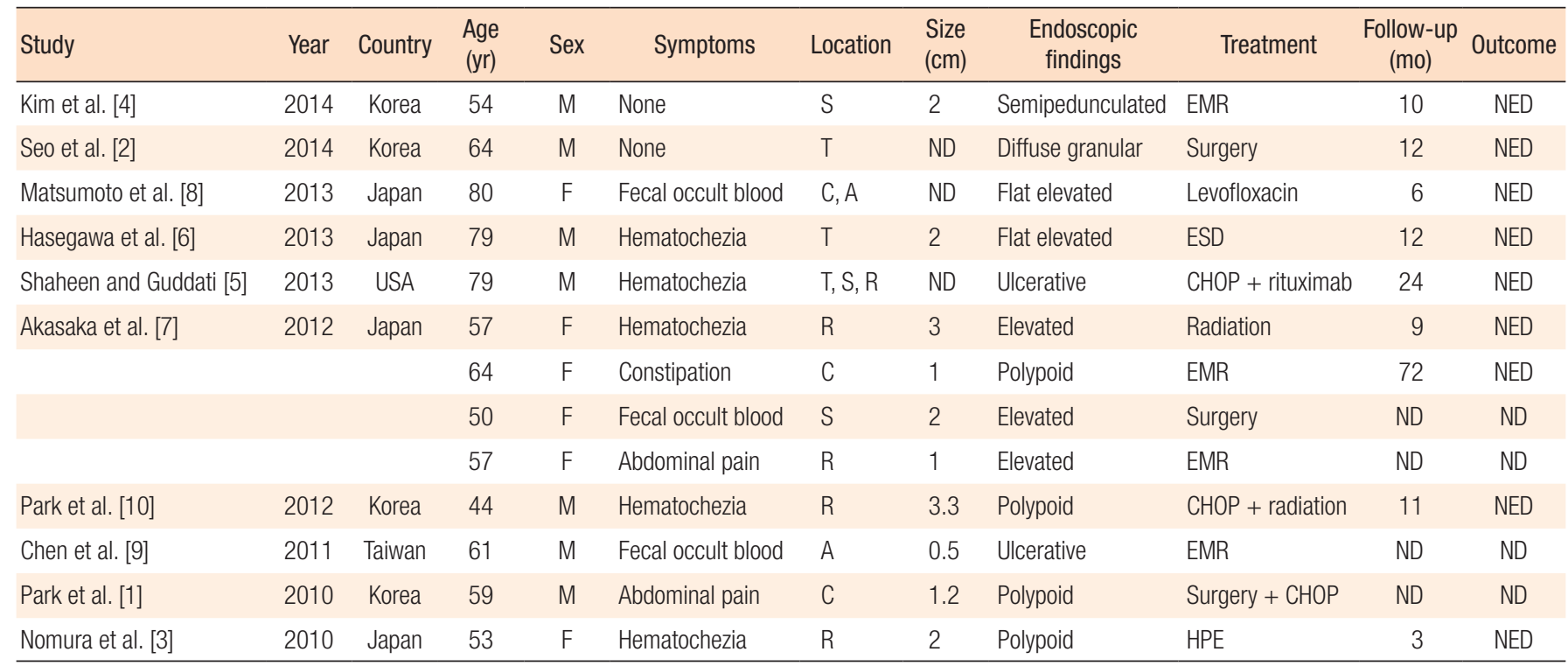

$\mathrm{R}$, rectum; $\mathrm{S}$, sigmoid colon; T, transverse colon; $\mathrm{A}$, ascending colon; C, cecum; EMR, endoscopic mucosal resection; ESD, dissection endoscopic submucosal dissection; HPE, Helicobacter pylori eradicawtion; ND, not described; NED, no evidence of disease; CHOP, cyclophosphamide, hydroxydaunomycin, oncovin, prednisolone.

of extra nodal gastric MALT lymphomas [3]. Matsumoto et al. [8] reported the case of an 80-year-old man, who had presented with a progression of a residual lesion 1 year after $H$. pylori eradication and who was treated with levofloxacin for 14 days as a secondline therapy. Although most patients in these studies presented with symptoms such as abdominal pain, hematochezia, or positive fecal occult blood, 2 reports described 2 patients without any symptoms, in whom the MALT lymphoma had been revealed by using screening colonoscopy as in the present case [2, 4, 9]. Many colorectal MALT lymphomas present as elevated lesions, such as polyps or subepithelial tumors. For that reason, endoscopic ultrasonography is useful for establishing a diagnosis. Park et al. [10] reported the case of a patient with a protruding subepithelial tumor in the rectum, which had diagnosed using the endoscopic unroofing technique and then treated by using chemoradiation therapy.

Various reports have been published on the treatment of patients with a colorectal MALT lymphoma; those treatments include surgery, chemotherapy, radiation therapy, endoscopic resection, and $H$. pylori eradication. Nevertheless, controversy exists with regards to antibiotic treatment or observation because of the unknown pathogenesis of a primary colorectal MALT lymphoma. Therefore, the patient's individual condition, such as age and extent of disease or comorbidity, should be considered when deciding on a treatment for a patient with a MALT lymphoma in the colon and rectum. More studies addressing various features are needed before standard treatment guidelines can be established for treating patients with a colorectal MALT lymphoma.

\section{CONFLICTS OF INTEREST}

No potential conflict of interest relevant to this article was reported.

\section{REFERENCES}

1. Park JH, Lee JH. MALT (Mucosa-Associated Lymphoid Tissue) Lymphoma of the colon. Korean J Gastroenterol 2010;55:213-6.

2. Seo SW, Lee SH, Lee DJ, Kim KM, Kang JK, Kim DW, et al. Colonic mucosa-associated lymphoid tissue lymphoma identified by chromoendoscopy. World J Gastroenterol 2014;20:18487-94.

3. Nomura E, Uchimi K, Abue M, Kon H, Noguchi T, Suzuki S, et al. Regression of MALT lymphoma of the rectum after Helicobacter pylori eradication therapy in a patient negative for Helicobacter pylori. Nihon Shokakibyo Gakkai Zasshi 2010;107:146673.

4. Kim MH, Jung JT, Kim EJ, Kim TW, Kim SY, Kwon JG, et al. A case of mucosa-associated lymphoid tissue lymphoma of the sigmoid colon presenting as a semipedunculated polyp. Clin Endosc 2014;47:192-6.

5. Shaheen S, Guddati AK. Secondary mucosa-associated lymphoid tissue (MALT) lymphoma of the colon. Med Oncol 2013;30:502.

6. Hasegawa D, Yoshida N, Ishii M, Takamasu M, Kishimoto M, Yagi $\mathrm{N}$, et al. A case of colonic mucosa-associated lymphoid tissue lymphoma observed under endoscopy with narrow-band imaging. Nihon Shokakibyo Gakkai Zasshi 2013;110:2100-6.

7. Akasaka R, Chiba T, Dutta AK, Toya Y, Mizutani T, Shozushima T, et al. Colonic mucosa-associated lymphoid tissue lymphoma. 


\section{Coloproctology}

Case Rep Gastroenterol 2012;6:569-75.

8. Matsumoto T, Inokuma T, Imai Y. Education and imaging. Gastrointestinal: colonic mucosa-associated lymphoid tissue lymphoma regressed by levofloxacin. J Gastroenterol Hepatol 2013;28:750.

9. Chen PH, Lin YM, Yen HH. Primary mucosa-associated lymphoid tissue lymphoma of the colon. Clin Gastroenterol Hepatol 2011;9:e74-5.

10. Park H, Chung JW, Kim AJ, Park SY, Rim MY, Jang YR, et al. A case of rectal mucosa-associated lymphoid tissue lymphoma diagnosed by endoscopic unroofing technique. Korean J Gastroenterol 2012;59:428-32. 